\title{
Prognostic Role of MicroRNA-221 in Various Human Malignant Neoplasms: A Meta-Analysis of 20 Related Studies
}

\author{
Jie Yang ${ }^{19}$, Jia-yi Zhang ${ }^{19}$, Jing Chen ${ }^{29}$, Yang Xu ${ }^{1}$, Ning-hong Song ${ }^{1}$, Chang-jun Yin ${ }^{1 *}$ \\ 1 Department of Urology, First Affiliated Hospital of Nanjing Medical University, Nanjing, Jiangsu, China, 2 Department of General Surgery, Nanjing First Hospital Affiliated \\ to Nanjing Medical University, Nanjing, Jiangsu, China
}

\begin{abstract}
Background: MicroRNA-221 (miR-221) has been shown to play an important role in cancer prognosis. In order to evaluate the predictive value of miR-221, we compiled the evidence from 20 eligible studies to perform a meta-analysis.

Design: All of relevant studies were identified by searching PubMed, Embase, and Web of Science, and were assessed by further quality evaluation. Pooled hazard ratios (HRs) with $95 \%$ confidence intervals (Cls) of total and stratified analyses, for overall survival (OS) and recurrence-free survival (RFS), were calculated to investigate the association between high miR-221 expression and cancer prognosis.

Results: We found that high miR-221 expression can predict a poor OS in malignant tumors (pooled HR $=1.55, \mathrm{P}=0.017$ ) but has no significant association with RFS (pooled $H R=1.02, P=0.942)$. Further in stratified analyses, high miR-221 expression was significantly associated with a poor OS in Asians (pooled $H R=2.04, P=0.010$ ) or serum/ plasma subgroup (pooled $H R=2.28, P<0.001$ ), and even showed significantly poor OS (pooled $H R=1.80, P<0.001$ ) and $R F S$ (pooled $H R=2.43$, $\mathrm{P}=0.010)$ in hepatocellular carcinoma (HCC) subgroup, but was correlated to a favorable RFS in prostate cancer subgroup (pooled HR=0.51, $\mathrm{P}=0.004$ ).

Conclusions: Our findings demonstrate that miR-221 is more suitable to predict cancer prognosis in Asians, and it is a promising prognostic biomarker for HCC. The detection of miR-221 in serum or plasma samples may make it become an effective method for monitoring patients' prognosis and assessing therapeutic efficacy in the future.
\end{abstract}

Citation: Yang J, Zhang J-y, Chen J, Xu Y, Song N-h, et al. (2014) Prognostic Role of MicroRNA-221 in Various Human Malignant Neoplasms: A Meta-Analysis of 20 Related Studies. PLoS ONE 9(1): e87606. doi:10.1371/journal.pone.0087606

Editor: Lin Zhang, University of Pennsylvania School of Medicine, United States of America

Received October 29, 2013; Accepted December 23, 2013; Published January 27, 2014

Copyright: (c) 2014 Yang et al. This is an open-access article distributed under the terms of the Creative Commons Attribution License, which permits unrestricted use, distribution, and reproduction in any medium, provided the original author and source are credited.

Funding: The authors have no support or funding to report.

Competing Interests: The authors have declared that no competing interests exist.

*E-mail: drcjyin@163.com

9 These authors contributed equally to this work.

\section{Introduction}

Since the discovery of microRNAs (miRNAs) in 1993 [1], emerging studies have suggested that miRNAs are potential regulators of a wide range of biological processes including development, cell differentiation, proliferation, and apoptosis [28]. MiRNAs are endogenous, small, single-stranded, non-coding RNAs, which negatively regulate gene expression at posttranscriptional level [3]. Aberrant expression of many miRNAs has been discovered in various human carcinomas [9-13], so more and more researchers are willing to consider multifarious miRNAs as diagnostic or prognostic biomarkers.

MicroRNA-221 (miR-221), encoded on human chromosome X, is overexpressed in many aggressive carcinomas [14-17]. It has been observed that there is an inverse relationship between the expression of miR-221 and some cell cycle inhibitors, such as p27Kip1 [18-21]. Abnormal overexpression of miR-221 strongly facilitates tumor cell growth by inducing cell lines in vitro to progress into the $\mathrm{S}$ phase of cell cycle $[20,22]$. Recently, studies have discovered that miR-221 is significantly up-regulated in cell lines [23-26], plasma or serum [27-32], and tissues [33-39] of numerous human malignancies. Data from clinical studies also indicate that high miR-221 expression is correlated with poor prognosis in glioma [25,36,37], breast cancer [15,16,40], multiple myeloma [19,41], hepatocellular carcinoma (HCG) [42-44], pancreatic cancer [24,33], T-cell acute lymphoid leukemia (TALL) $[35,45]$, and gastric cancer [26,38]. Furthermore, elevated expression of miR-221 in certain carcinomas is obviously related to a trend of easier invasion [15-17,36,38,47,48], larger tumor size $[17,30,47]$, earlier metastasis $[17,38,46]$ and shorter time to recurrence $[30,39,48]$.

However, controversy about the oncogenic role of miR-221 still exists. Some studies draw statistically insignificant conclusions $[37,40,43,49-51]$, and even some come to completely opposite results [52-54]. Regardless of these inconsistent outcomes, miR221 is still considered an attractive biomarker for the assessment of cancer survival and recurrence. Therefore, we conducted a meta- 
analysis to clarify the accurate role of miR-221 for OS and RFS in multiple human malignant neoplasms.

\section{Materials and Methods}

\section{Search strategy}

We conducted an online search using PubMed, Embase and Web of Science for original articles analyzing the prognostic value of miR-221 in various cancers. We selected studies according to varying combinations of the following sets of keywords: 'cancer', 'carcinoma', 'neoplasm', 'tumour', 'tumor', 'microRNA-221', 'microrna-221', 'miRNA-221', 'miR-221', 'overall survival', 'recurrence', and 'prognosis'. The last search update was performed on August 28, 2013. All eligible studies published in English were reviewed, and their bibliographies were also examined for other relevant publications. Relevant review articles were manually searched to find additional eligible studies. If more than one article had been published using the same series of study subjects, we only chose the most recent or complete study for this meta-analysis.

\section{Inclusion and exclusion criteria}

We followed the guidelines of Preferred Reporting Items for Systematic Reviews and Meta-Analysis (PRISMA) Statement issued in 2009. Articles were considered eligible when they fit the following criteria: (i) MiR-221 was involved in the research; (ii) patients with any malignant tumor were studied; (iii) the relationship between miR-221 expression levels and patients' survival outcomes was investigated. Studies that met above mentioned eligibility criteria were further evaluated and excluded based on a selection process presented in Figure 1.

\section{Data extraction}

All data were carefully extracted, in duplicate, from the eligible publications by two co-authors (J.Y. and J.C.), and any disagreements were resolved by discussion between the two authors. The extracted data elements were exhibited in Table 1 and 2. If HRs and $95 \%$ CIs were not reported directly, we extracted the data from Kaplan-Meier curves of survival outcomes to extrapolate required data using the previously described methods [55-57]. We also sent e-mails to the corresponding authors of eligible articles requesting additional information and original data needed for the meta-analysis.

\section{Statistical analysis}

All statistical analyses were conducted using Stata ${ }^{\circledR} 11$ (StataCorp LP, College Station, TX, USA) and Microsoft Excel (Version 2007, Microsoft corp., Redmond, WA, USA). The aggregation of HRs and 95\% CIs were calculated following Tierney's method [57]. Forest plots were used to estimate the effect of miR-221 expression on survival outcome (OS and RFS). The heterogeneity assumption of pooled HRs was verified by Cochran's Q-test, and the percentage of Higgins I-squared statistic $\left(\mathrm{I}^{2}\right)$ was used to quantify the extent of heterogeneity explained by the characteristics of enrolled studies. If significant heterogeneity was observed $\left(\mathrm{P}<0.1\right.$ or $\left.\mathrm{I}^{2}>50 \%\right)$, a random-effects model (DerSimonian-Laird method) was applied, otherwise the fixedeffects model (Mantel-Haenszel method) was used [58]. To avoid the influence of heterogeneity, we also conducted subgroup analyses based on similar characteristics, such as dominant ethnicity, main type of pathology, and detected sample category. Potential publication bias was determined by Egger's linear regression test with a funnel plot [59]. All $\mathrm{P}$ values were twosided and a $\mathrm{P}$ value of less than 0.05 was considered to be statistically significant.

\section{Potential relevant articles identified and screened for retrieval $(n=556)$}

\begin{tabular}{|l|l|}
\hline $\begin{array}{l}483 \text { excluded due to the following criteria: } \\
\text { Reivew articles or letters } \\
\text { Not a human study } \\
\text { Non-English articles } \\
\text { Unrelated to survival or prognosis } \\
\text { Unrelated to any malignant neoplasms } \\
\text { Unrelated to microRNA-221 } \\
\text { Absence of key information }\end{array}$ \\
\hline Further quality evaluation of details (n=73) \\
\hline Articles included in the review ( $\mathrm{n}=20 ; 15$ had outcome data reported by their authors) \\
\hline
\end{tabular}

Figure 1. Flow diagram of study selection process. doi:10.1371/journal.pone.0087606.g001 


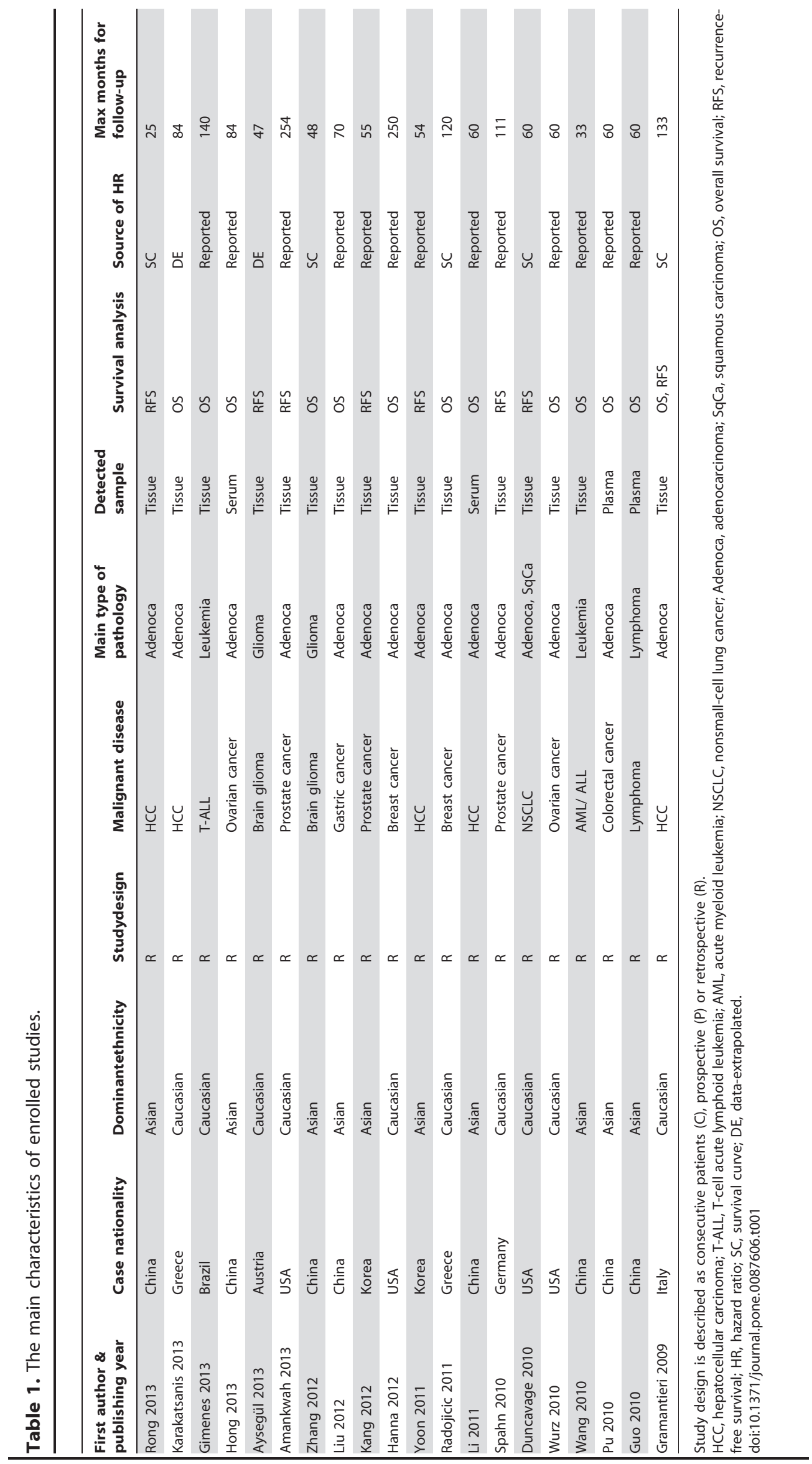


Table 2. The difference of overall survival and recurrence-free survival between high- and low-expression cases of microRNA-221 in enrolled studies.

\begin{tabular}{|c|c|c|c|c|c|c|c|c|}
\hline \multirow[t]{2}{*}{$\begin{array}{l}\text { First author \& } \\
\text { publishing year }\end{array}$} & \multirow[t]{2}{*}{$\begin{array}{l}\text { Assay } \\
\text { method }\end{array}$} & \multirow[t]{2}{*}{ Cut-off value } & \multicolumn{2}{|l|}{ Case number } & \multicolumn{2}{|l|}{ os } & \multicolumn{2}{|l|}{ RFS } \\
\hline & & & high expression & low expression & HR (95\% Cl) & $\mathbf{P}$ & HR (95\% Cl) & $\mathbf{P}$ \\
\hline Rong 2013 & qRT-PCR & Median & 24 & 24 & NM & NM & $1.60(0.88,2.90)^{U_{*}}$ & 0.129 \\
\hline Karakatsanis 2013 & qRT-PCR & Mean & NM & NM & $1.79(1.50,2.13)^{\mathrm{M}, \mathrm{DE}}$ & 0.000 & NM & NM \\
\hline Gimenes 2013 & qRT-PCR & Median & 24 & 24 & $2.31(0.92,5.81)^{\mathrm{M}}$ & 0.074 & NM & NM \\
\hline Hong 2013 & qRT-PCR & Mean & 51 & 45 & $2.24(1.13,4.48)^{\mathrm{M}}$ & 0.020 & NM & NM \\
\hline Aysegül 2013 & qRT-PCR & Median & 5 & 10 & NM & NM & $1.11(0.37,3.35)^{\mathrm{DE}}$ & 0.855 \\
\hline Amankwah 2013 & qRT-PCR & Median & 28 & 35 & NM & NM & $0.56(0.21,1.50)^{\mathrm{M}}$ & 0.250 \\
\hline Zhang 2012 & qRT-PCR & Mean & 22 & 14 & $2.62(1.19,5.75)^{\mathrm{U}_{*}}$ & 0.011 & NM & NM \\
\hline Liu 2012 & qRT-PCR & Mean & 48 & 44 & $2.32(1.11,4.85)^{\mathrm{M}, \mathrm{DE}}$ & 0.025 & NM & NM \\
\hline Kang 2012 & qRT-PCR & Median & NM & NM & NM & NM & $0.36(0.17,1.90)^{\mathrm{U}}$ & 0.570 \\
\hline Hanna 2012 & qRT-PCR & Highest tertile & 354 & 119 & $0.70(0.51,0.97)^{\mathrm{M}}$ & 0.312 & NM & NM \\
\hline Yoon 2011 & qRT-PCR & Mean & 30 & 85 & NM & NM & $2.09(1.09,4.04)^{\mathrm{M}}$ & 0.027 \\
\hline Radojicic 2011 & qRT-PCR & Median & 49 & 38 & $1.62(0.76,3.47)^{U_{*}}$ & 0.458 & NM & NM \\
\hline Li 2011 & qRT-PCR & 4.8 -fold & 21 & 25 & $1.90(1.24,2.98)^{\mathrm{U}}$ & $<0.05$ & NM & NM \\
\hline Spahn 2010 & qRT-PCR & Median & 49 & 43 & NM & NM & $0.53(0.29,0.95)^{\mathrm{M}}$ & 0.032 \\
\hline Duncavage 2010 & qRT-PCR & Mean & 20 & 21 & NM & NM & $0.41(0.14,1.15)^{U_{*}}$ & 0.120 \\
\hline Wurz 2010 & qRT-PCR & Median & NM & NM & $0.32(0.13,0.82)^{u}$ & 0.010 & NM & NM \\
\hline Wang 2010 & qRT-PCR & Median & 16 & 16 & $0.54(0.30,0.97)^{U, D E}$ & 0.038 & NM & NM \\
\hline Pu 2010 & qRT-PCR & Mean & 19 & 80 & $3.48(1.04,11.65)^{\mathrm{M}}$ & 0.043 & NM & NM \\
\hline Guo 2010 & qRT-PCR & Mean & 50 & 29 & $5.71(1.78,18.18)^{\mathrm{M}}$ & 0.003 & NM & NM \\
\hline Gramantieri 2009 & qRT-PCR & Median & 21 & 25 & $1.64(0.67,4.05)^{\mathrm{U}_{*}}$ & 0.500 & $6.60(2.15,20.21)^{U_{*}}$ & 0.001 \\
\hline
\end{tabular}

qRT-PCR, quantitative real-time PCR; NM, not mentioned; OS, overall survival; $\mathrm{Cl}$, confidence interval; RFS, recurrence-free survival; $\mathrm{HR}$, hazard ratio; *, HR and 95\% CI calculated by survival curve; $\mathrm{M}$, cox multivariate analysis; $\mathrm{U}$, cox univariate analysis; $\mathrm{DE}$, data-extrapolated.

doi:10.1371/journal.pone.0087606.t002

\section{Results}

\section{Summary of included studies}

According to the study selection process, 556 studies on miR221 and cancer were identified from a primary literature search in Pubmed, Embase, and Web of Science. Four hundred eighty-three studies were excluded based on manual screening of the title and the abstract, and 53 were further removed by assessment on the full text (Figure 1). Finally, 20 studies, which investigated the potential relationship between miR-221 expression and patients' survival or disease recurrence in various malignant neoplasms, were considered eligible for this meta-analysis.

Analyzed data of enrolled studies were collected from the United States, Germany, Greece, Italy, Austria, China, Korea, and Brazil. The dominant ethnicity was Caucasian in half of the enrolled studies, while the other 10 studies were executed in Asians. All of the studies were retrospective in design, and the maximum follow-up was from 25 to 254 months. The malignant diseases involved in this review included HCC, acute leukemia, ovarian cancer, glioma, prostate cancer $(\mathrm{PCa})$, gastric cancer, breast cancer, non-small cell lung cancer (NSGLG), colorectal cancer (CRC), and lymphoma. The expression level of miR-221 was usually detected by quantitative real-time polymerase chain reaction (qRT-PCR) assay in tissue samples, while four studies tested it in plasma or serum samples. (Table 1)

Among these studies, 12 focused on OS, seven were associated with RFS, and one evaluated both OS and RFS. Thirteen studies directly reported HRs and 95\% CIs. We calculated these necessary statistical variables by survival curves in five studies, and extrapolated them based on available numerical data in the other two studies. (Table 1)

\section{High miR-221 expression and overall survival}

A total of 13 articles were involved in OS analysis (Table 2, Figure 2A), among which significant heterogeneity was observed $\left(\mathrm{P}=0.000, \mathrm{I}^{2}=80.5 \%\right)$. Hence, a random model was applied to calculate a pooled $\mathrm{HR}$ and $95 \% \mathrm{CI}$, and we found that patients with high miR-221 expression had a significantly poorer OS when compared to individuals with a low expression of miR-221 $(\mathrm{HR}=1.55,95 \%$ CI, 1.08-2.22) (Table 3).

In order to avoid the influence of heterogeneity, we conducted four subtotal analyses stratified by dominant ethnicity, main pathologic type, categories of detected samples, and malignant diseases. First, seven studies in Asians [29-32,36,38,52] showed that increased expression of miR-221 predicted a significantly worse $\mathrm{OS}(\mathrm{HR}=2.04,95 \%$ CI: $1.19-3.49)$ by a random-effects model due to significant heterogeneity among pooled studies $\left(\mathrm{P}=0.001, \mathrm{I}^{2}=73.7 \%\right)$. We didn't find a significantly worse OS in Caucasians with high miR-221 expression by merging six studies $[35,40,44,47,51,53]$ (Figure 2A). In subtotal analyses of main pathologic type category, no statistically significant result was observed in adenocarcinoma and leukemia/lymphoma subgroup (Figure 3A). When stratified by the category of detected samples, increased expression of miR-221 showed a significant association with poor $\mathrm{OS}(\mathrm{HR}=2.28,95 \%$ CI: $1.62-3.19)$ by a fixed-effects model $\left(\mathrm{P}=0.316, \mathrm{I}^{2}=15.2 \%\right)$ in serum/plasma subgroup [29-32], 

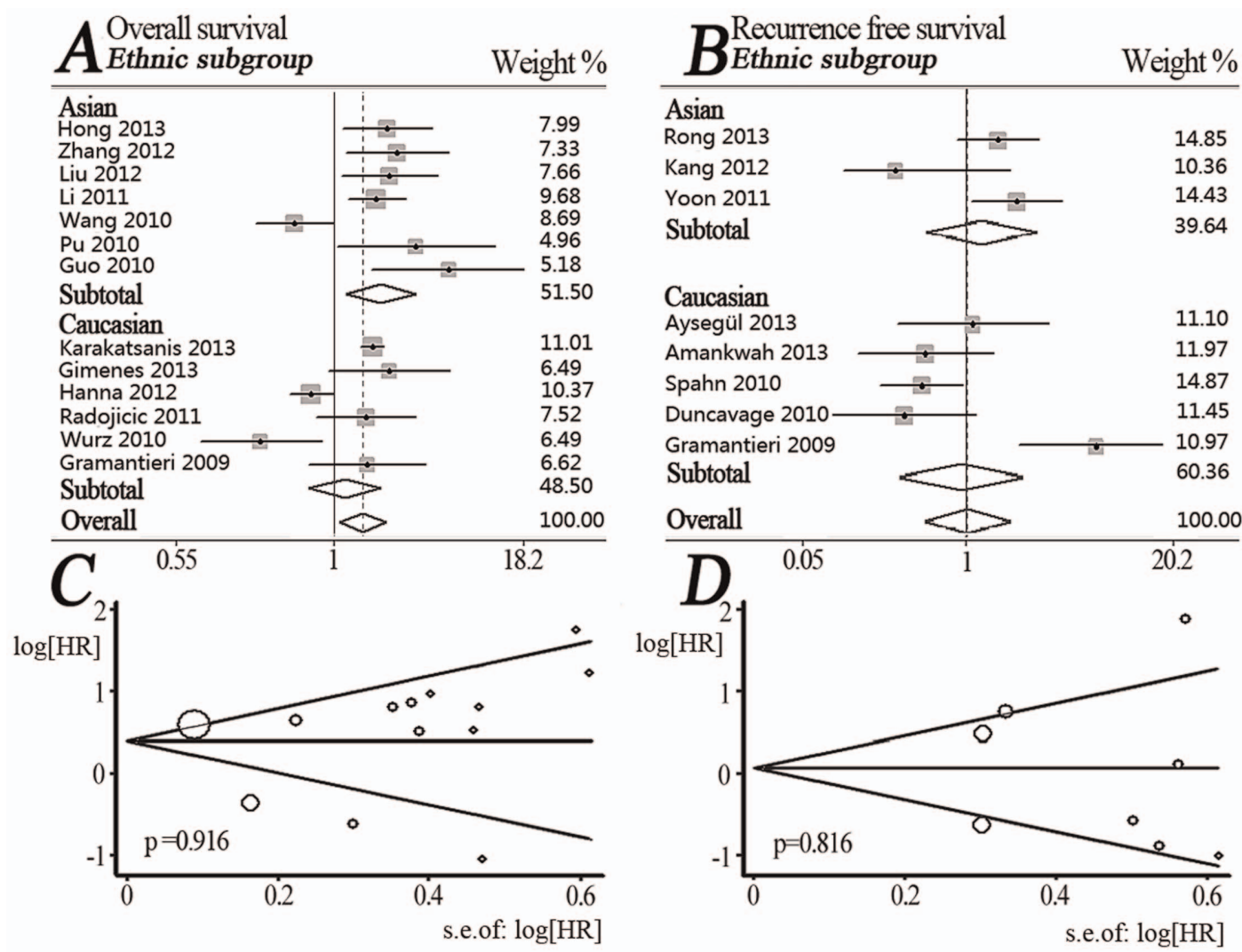

Figure 2. Forest plots for merged analyses of overall survival (OS) and recurrence-free survival (RFS) associated with miR-221 expression difference, and Begg's funnel plots of publication bias test. (A) Forest plots of overall and ethnic subtotal analyses of OS. Squares and horizontal lines correspond to study-specific HRs and $95 \% \mathrm{Cls}$, respectively. The area of the squares correlates the weight of each enrolled study and the diamonds represent the summary HRs and $95 \% \mathrm{Cls}$; (B) Forest plots for overall and ethnic subtotal analyses of RFS; (C) Begg's funnel plots of publication bias test for the overall merged analysis of OS. Each point represents a separate study; (D) Begg's funnel plots of the publication bias test for the overall merged analysis of RFS.

doi:10.1371/journal.pone.0087606.g002

but no significant relationship was observed in tissue subgroup (Figure 3B). Moreover, in subtotal analysis stratified by the category of malignant diseases, three studies of HCG [30,44,47] exhibited a significant association between increased expression of miR-221 and poor OS (HR $=1.80,95 \%$ CI: $1.53-2.11)$ by a fixedeffects model $\left(\mathrm{P}=0.950, \mathrm{I}^{2}=0.0 \%\right)$. However, we did not discover any significant association in subgroups of ovarian cancer or breast cancer (Figure 3G).

3 High miR-221 expression and recurrence-free survival

A total of eight studies focused on RFS analysis (Table 2, Figure 2B) with a significant heterogeneity among them $\left(\mathrm{P}=0.000, \mathrm{I}^{2}=76.1 \%\right)$. A random-effects model was applied for merging overall data, but no obvious relationship between increased expression of miR-221 and RFS was observed $(\mathrm{HR}=1.02,95 \%$ CI: 0.55-1.89) (Table 3).

Similar to OS analyses, we also performed subtotal investigation for RFS analyses. When stratified by dominant ethnicity, no significant association was observed in both Caucasians and Asians (Figure 2B). In subtotal analyses of main pathological type, the pooled outcome of adenocarcinoma subgroup did not reveal high miR-221 expression could significantly predict a poor RFS (Figure 3D). When stratified by the category of detected samples, the outcome of tissue subgroup also didn't show statistical significance (Figure 3E). Finally, stratified by the category of malignant diseases, elevated expression of miR-221 exhibited a significant association with poor RFS (HR $=2.43,95 \%$ CI: 1.24 $4.77)$ in HCC $[39,43,47]$ by a random-effects model $(\mathrm{P}=0.091$, $\left.\mathrm{I}^{2}=58.3 \%\right)$. However, the pooled outcome in PCa subgroup $[48,49,54]$ surprisingly showed elevated miR-221 expression was significantly associated with a favorable RFS (HR $=0.51,95 \% \mathrm{CI}$ : $0.32-0.81)$ by a fixed-effects model $\left(\mathrm{P}=0.831 ; \quad \mathrm{I}^{2}=0.0 \%\right)$ (Figure 3F).

\section{Publication bias}

Publication bias, for total OS or RFS analyses, was respectively evaluated by funnel plots. The shape of all funnel plots seemed symmetrical suggesting absence of a publication bias (Figure 2C and 2D). Egger's test was used to provide statistical evidence for funnel plot symmetry. As expected, the $\mathrm{P}$ value of Egger's test was 0.916 for OS and 0.816 for RFS. Hence, there was no evidence for significant publication bias in the meta-analysis.

\section{Discussion}

Compared to mRNAs, miRNAs are more stable and not easily degraded. They exhibit a special expression profile in various normal and malignant tissues, which can be accurately detected and quantified by qRT-PCR [60] not only in frozen or fresh tissues, but also in formalin-fixed paraffin-embedded tissues. They can also be quantified in serum or plasma samples, and even in urine or saliva samples [61]. In recent studies, miR-221 has been 
Table 3. The pooled HRs, $95 \% \mathrm{Cls}$ and $\mathrm{p}$ values of overall survival and recurrence-free survival stratified by ethnicity, main pathologic type, categories of malignant diseases and detected samples.

\begin{tabular}{|c|c|c|c|c|c|c|}
\hline \multirow{2}{*}{ Subgroup } & \multicolumn{3}{|c|}{ Overall survival } & \multicolumn{3}{|c|}{ Recurrence free survival } \\
\hline & $\mathbf{N}$ & HR (95\% Cl) & p value & $\mathbf{N}$ & HR $(95 \% \mathrm{Cl})$ & $p$ value \\
\hline Total & 13 & $1.55(1.08,2.22)^{b}$ & 0.017 & 8 & $1.02(0.55,1.89)^{b}$ & 0.942 \\
\hline \multicolumn{7}{|l|}{ Ethnic subtotal } \\
\hline Caucasian & 6 & $1.17(0.67,2.03)^{b}$ & 0.578 & 5 & $0.94(0.39,2.27)^{b}$ & 0.883 \\
\hline Asian & 7 & $2.04(1.19,3.49)^{b}$ & 0.010 & 3 & $1.25(0.56,2.77)^{b}$ & 0.586 \\
\hline \multicolumn{7}{|l|}{ Main pathologic subtotal } \\
\hline Adenocarcinoma & 9 & $1.46(0.98,2.18)^{b}$ & 0.062 & 6 & $1.16(0.55,2.42)^{b}$ & 0.698 \\
\hline Leukemia or lymphoma & 3 & $1.80(0.44,7.41)^{b}$ & 0.415 & - & - & - \\
\hline \multicolumn{7}{|l|}{ Malignant disease subtotal } \\
\hline Hepatocellular carcinoma & 3 & $1.80(1.53,2.11)^{\mathrm{a}}$ & $<0.001$ & 3 & $2.43(1.24,4.77)^{b}$ & 0.010 \\
\hline Ovarian cancer & 2 & $0.87(0.13,5.84)^{b}$ & 0.884 & - & - & - \\
\hline Breast cancer & 2 & $0.99(0.44,2.22)^{b}$ & 0.980 & - & - & - \\
\hline Prostate cancer & - & - & - & 3 & $0.51(0.32,0.81)^{\mathrm{a}}$ & 0.004 \\
\hline \multicolumn{7}{|l|}{ Detected sample subtotal } \\
\hline Tissue & 9 & $1.25(0.80,1.95)^{b}$ & 0.336 & 8 & $1.02(0.55,1.89)^{b}$ & 0.942 \\
\hline Serum or plasma & 4 & $2.28(1.62,3.19)^{\mathrm{a}}$ & $<0.001$ & - & - & - \\
\hline
\end{tabular}

$\mathrm{N}$, number of studies; $\mathrm{HR}$, hazard ratio; $\mathrm{Cl}$, confidence interval.

$a$, the HRs and $95 \% \mathrm{Cls}$ of enrolled studies are pooled by the fixed-effects model; $b$, the HRs and $95 \%$ Cls of enrolled studies are pooled by the random-effects model if $p$ value for heterogeneity test was less than 0.10 or $\mathrm{I}^{2}$ was more than $50 \%$.

doi:10.1371/journal.pone.0087606.t003

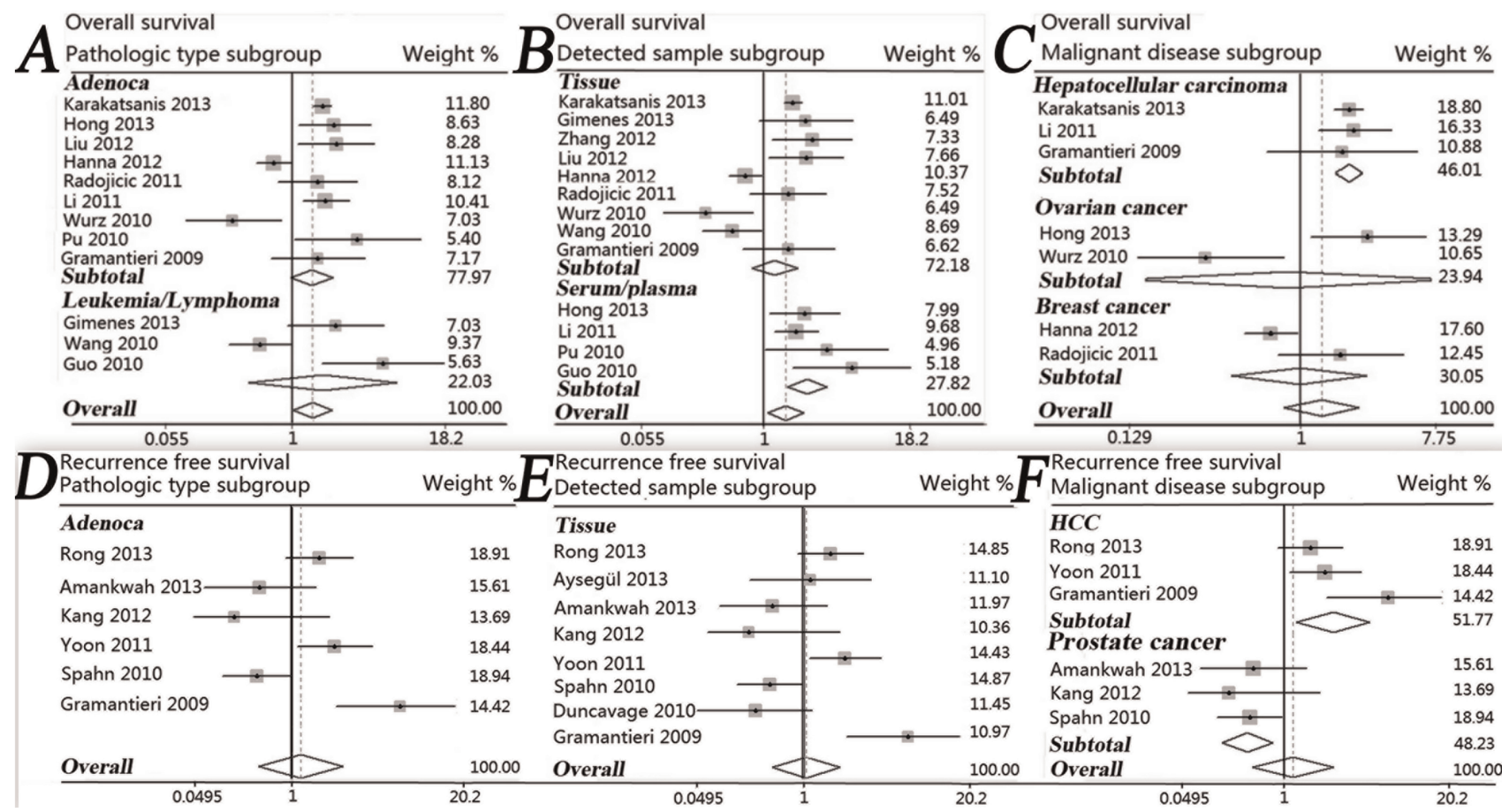

Figure 3. Forest plots for merged analyses of overall survival (OS) and recurrence-free survival (RFS), associated with miR-221 expression difference, in different subgroups. (A) Forest plots for the subgroup analysis of OS in different pathological types. Squares and horizontal lines correspond to study-specific $\mathrm{HRs}$ and $95 \% \mathrm{Cls}$, respectively. The area of the squares correlates the weight of each enrolled study and the diamonds represent the summary HRs and $95 \% \mathrm{Cls}$; (B) Forest plots for the subgroup analysis of OS in different detected samples; (C) Forest plots for the subgroup analysis of OS in different malignant diseases; (D) Forest plots for the subgroup analysis of RFS in adenocarcinoma; (E) Forest plots for the subgroup analysis of RFS in tissue samples; (F) Forest plots for the subgroup analysis of RFS in different malignant diseases. doi:10.1371/journal.pone.0087606.g003 
found closely associated with tumors by intricate regulatory mechanisms, in which several target genes of miR-221 affect tumorigenesis and progression. For instance, miR-221 can suppress the expression of cell cycle regulators, p27Kipl and p57Kip2 mRNA, in multiple cancers to induce the proliferation of tumor cells [18-21]. MiR-221 also blocks the migration and proliferation of tumor cells and the angiogenesis of tumor tissues by targeting c-kit, the stem cell factor receptor [62]. Moreover, increased expression of miR-221 is able to inhibit cell apoptosis in HCG by negatively regulating Bcl2 modifying factor (BMF), a well-known factor involved in the balance between proapoptosis and antiapoptosis [47]. Pu et al find that the expression of p53, a tumor suppressor, is negatively correlated with the plasma level of miR-221, and suggest that p53 might repress miR-221 expression in CRC [31]. Zhang et al confirm that miR-221 directly inhibits the posttranscriptional expression of metallopeptidase inhibitor 3 (TIMP3), an inhibitor of matrix metalloproteinases (MMPs), and plays an important role in promoting the invasion of human gliomas [36]. The oncogenic effect of miR-221 is also mediated by phosphatase and tensin homolog (PTEN) [38]. Currently, a number of clinical studies have shown a significant correlation between the expression level of miR-221 and the prognosis of various malignant tumors [29-32]. However, the results are not consistent and even contradictory, which may be due to the differences in disease categories, ethnic affiliations, and detected samples. Therefore, it is necessary to conduct stratified pooled analyses to identify the prognostic value of miR-221 in survival and recurrence, as well as its application scope.

By stratified analyses of enrolled studies, we successfully drew some valuable conclusions for clinical application. First, in order to exclude the interference caused by the different genetic backgrounds of patients, the 20 enrolled studies were classified based on ethnic affiliation into Asians and Caucasians (Table 1). We found increased miR-221 expression predicts a significantly worse OS in Asians (pooled HR=2.04, $\mathrm{P}=0.010$ ), but there was no statistical significance in Caucasians (pooled $\mathrm{HR}=1.17$, $\mathrm{P}=0.578$ ). This observation may be due to the difference in hereditary backgrounds and environmental exposures. Plenty of researches have also shown different expression levels and predictive values of miRNAs in various ethnic groups [63-65]. Therefore, we consider that diverse hereditary backgrounds and environmental exposures give rise to different predictive values of miR-221 in cancer prognosis, and miR-221 is more suitable as a tumor biomarker for prognosis in Asians.

Second, we performed subgroup analyses on the basis of pathological types. Due to the limited number of eligible studies, only two subgroups of adenocarcinoma and leukemia/lymphoma could be further analyzed, however, we failed to find any statistically significant results in the two subgroups (Table 3, Figure 3). Hence the type of tumors, in which miR-221 can be suitably utilized as a prognostic marker, still needs to be determined.

To further exclude the differences of tumorigenesis and development mechanisms among various cancers, we classified the enrolled studies into subgroups of cancer categories. It was observed that high miR-221 expression is significantly associated with both poor OS (pooled HR $=1.80, \mathrm{P}<0.001$ ) and RFS (pooled $\mathrm{HR}=2.43, \mathrm{P}=0.010$ ) in HCC (Table 3, Figure 3). HCG patients with high miR-221 expression exhibit a significantly decreased survival rate and a significantly increased recurrence rate than those with low expression of miR-221. It may be because that elevated miR-221 may be able to induce tumor cell proliferation by negatively regulating the expression of $\mathrm{p} 27 \mathrm{Kip} 1$ and $\mathrm{p} 57 \mathrm{Kip} 2$, as well as inhibit cell apoptosis by suppressing the expression of
BMF [47]. Hence, we consider high miR-221 expression as a promising risk biomarker for poor prognosis in HCC. However, we draw a completely opposite conclusion in PCa subgroup $[48,49,54]$ where high miR-221 expression predicts a significantly lower recurrence risk (pooled $\mathrm{HR}=0.51, \mathrm{P}=0.004$ ). Spahn et al find that miR-221 is commonly down-regulated in $\mathrm{PCa}$, which has no relation with the mRNA levels of $\mathrm{p} 27 \mathrm{Kipl}$, but significantly correlates to the overexpression of c-kit [54]. Researchers, therefore, consider c-kit to play a key role in promoting tumorigenesis [54] and bone metastasis of PCa [66].

Finally, in order to clarify the prognostic values of miR-221 expression level in different clinical samples, we classified the enrolled studies into subgroups of tissue samples and serum/ plasma samples. We found that high expression of miR-221 significantly relates to a poor $\mathrm{OS}$ (pooled $\mathrm{HR}=2.28, \mathrm{P}<0.001)$ in serum/plasma subgroup. No statistical significance is shown in tissue subgroup (pooled $\mathrm{HR}=1.25, \mathrm{P}=0.336$ ) (Table 3, Figure 3). Although detection of miR-221 in tissue samples is widely used in current research for tumor prognosis, detection by serum/ plasma samples is more convenient and faster, which can effectively evaluate both survival prognosis and recurrence risk at any time point during or after clinical therapy, and even can keep monitored through the lifetime of patients. Therefore, detection of serum/ plasma miR-221 during follow-up may be an efficacious method for dynamically monitoring the prognosis and therapeutic effects in cancer patients.

These results indicate that miR-221 can be used for predicting cancer prognosis, and it is a promising biomarker. However, some details need to be further refined. First, there are only 20 eligible articles included in our analyses, which leads to the relative insufficiency of studies in subgroup analyses. When there are less than two studies for certain cancer prognoses, subgroup analysis cannot be carried out. Besides, there is no independent study in Africans for the meta-analysis, which hinders the comprehensive investigation of the association between miR-221 expression and cancer prognosis. Second, due to the lack of uniform cut-off value in miR-221 expression, different researchers apply different cut-off values, which may be higher or lower than the actual value and would affect the effectiveness of miR-221 as a predictive factor in cancer prognosis. Third, the pooled value of HR for total OS analysis is 1.55 in patients with high miR-221 expression, which is statistically significant $(\mathrm{P}=0.017)$ but not strong enough. Empirically, a predictive factor is considered to be strong when the value of HR is more than 2.0 [67]. Fourth, although the pooled outcome of three studies shows increased expression of miR-221 is significantly associated with a favorable RFS in PCa (pooled $\mathrm{HR}=0.51, \mathrm{P}=0.004)$, two of the three studies show no statistical significance (Table 2, Figure 3). Therefore, the value of miR-221 as a prognostic marker for PCa is still arguable, requiring more research for confirmation. Fifth, it still needs to be verified if miR221 can be used as an independent tumor biomarker, or if miR221 should be part of a combination of biomarkers utilized for predicting tumor prognosis. Using Cox proportional hazards regression analysis, Wang, et al evaluated a linear combination of the expression values of three miRNAs (miR-146a, miR-181a/c, and miR-221), and found that the combined value exhibited an obvious negative correlation to the OS of ALL patients $(\mathrm{r}=-0.5933, \mathrm{P}=0.0039)$. However when analyzed separately, high expression of miR-146a $(\mathrm{HR}=1.69, \mathrm{P}=0.039)$ and miR$181 \mathrm{a} / \mathrm{c}(\mathrm{HR}=1.70, \mathrm{P}=0.011)$ both indicate a significantly poor prognosis, whereas high miR-221 expression is associated with a favorable prognosis $(\mathrm{HR}=0.54, \mathrm{P}=0.038)$. In addition several drawbacks, such as a relatively small number of enrolled patients [37] or a short follow-up time [43], exist in individual studies. 
Therefore, further research on miR-221 for predicting cancer prognosis is required to confirm the prognostic role of miR-221.

Our meta-analysis also has some advantages. First, we strictly followed the literature inclusion criteria and the quality of enrolled literatures was satisfactory. Second, we conducted a multistratified analysis to effectively minimize the influence of heterogeneity among the enrolled studies, and to further explore the scope of application for miR-221 as a prognostic biomarker of malignant tumors. Third, no significant publication bias is found in our meta-analysis (Figure 2). All these advantages have increased the statistical power of the meta-analysis.

\section{Conclusions}

In summary, we conclude that miR-221 is suitable to predict tumor prognosis in Asian populations, and is an ideal prognostic biomarker for HCC patients. Besides, detecting miR-221 expression in serum/ plasma samples is more convincing to predict a poor prognosis than detection of miR-221 in tissue samples. Detection of miR-221 in human peripheral blood samples

\section{References}

1. Lee RC, Feinbaum RL, Ambros V (1993) The C. elegans heterochronic gene lin-4 encodes small RNAs with antisense complementarity to lin-14. Cell 75 : 843-54.

2. Fu G, Brkić J, Hayder H, Peng C (2013) MicroRNAs in Human Placental Development and Pregnancy Complications. Int J Mol Sci 14 (3): 5519-44.

3. DeCastro AJ, Dunphy KA, Hutchinson J, Balboni AL, Cherukuri P, et al. (2013) MiR203 mediates subversion of stem cell properties during mammary epithelial differentiation via repression of $\Delta \mathrm{NP} 63 \alpha$ and promotes mesenchymal-toepithelial transition. Cell Death Dis 4: e514.

4. Lu T, Shao N, Ji C (2013) Targeting microRNAs to modulate TRAIL-induced apoptosis of cancer cells. Cancer Gene Ther 20 (1): 33-7.

5. Luo M, Weng Y, Tang J, Hu M, Liu Q et al. (2012) MicroRNA-450a-3p represses cell proliferation and regulates embryo development by regulating Bubl expression in mouse. PLoS One 7 (10): e47914.

6. Jalali S, Ramanathan GK, Parthasarathy PT, Aljubran S, Galam L, et al. (2012) Mir-206 regulates pulmonary artery smooth muscle cell proliferation and differentiation. PLoS One 7 (10): e46808.

7. Bai Y, Liao H, Liu T, Zeng X, Xiao F, et al. (2013) MiR-296-3p regulates cell growth and multi-drug resistance of human glioblastoma by targeting ether-àgo-go (EAG1). Eur J Cancer 49 (3): 710-24.

8. Chen Y, Melton DW, Gelfond JA, McManus LM, Shireman PK (2012) MiR351 transiently increases during muscle regeneration and promotes progenitor cell proliferation and survival upon differentiation. Physiol Genomics 44 (21): $1042-51$.

9. Wu W, Sun M, Zou GM, Chen J (2007) MicroRNA and cancer: Current status and prospective. Int J Cancer 120 (5): 953-60.

10. Dudda JC, Salaun B, Ji Y, Palmer DC, Monnot GC, et al. (2013) MicroRNA155 Is Required for Effector CD8(+) T Cell Responses to Virus Infection and Cancer. Immunity 38 (4): 742-53.

11. Manavalan TT, Teng Y, Litchfield LM, Muluhngwi P, Al-Rayyan N, et al. (2013) Reduced Expression of miR-200 Family Members Contributes to Antiestrogen Resistance in LY2 Human Breast Cancer Cells. PLoS One 8 (4): e62334.

12. Lei H, Zou D, Li Z, Luo M, Dong L, et al. (2013) MicroRNA-219-2-3p Functions as a Tumor Suppressor in Gastric Cancer and Is Regulated by DNA Methylation. PLoS One 8 (4): e60369.

13. Ye J, Wu X, Wu D, Wu P, Ni C, et al. (2013) miRNA-27b Targets Vascular Endothelial Growth Factor C to Inhibit Tumor Progression and Angiogenesis in Colorectal Cancer. PLoS One 8 (4): e60687.

14. Galardi S, Mercatelli N, Giorda E, Massalini S, Frajese GV, et al. (2007) MiR221 and miR-222 expression affects the proliferation potential of human prostate carcinoma cell lines by targeting p27Kip1. J Biol Chem 282 (32): 23716-24.

15. Waters PS, McDermott AM, Wall D, Heneghan HM, Miller N, et al. (2012) Relationship between circulating and tissue microRNAs in a murine model of breast cancer. PLoS One 7 (11): e50459.

16. Nassirpour R, Mehta PP, Baxi SM, Yin MJ (2013) miR-221 Promotes Tumorigenesis in Human Triple Negative Breast Cancer Cells. PLoS One 8 (4): e62170.

17. Wang Z, Zhang H, He L, Dong W, Li J, et al. (2013) Association between the expression of four upregulated miRNAs and extrathyroidal invasion in papillary thyroid carcinoma. Onco Targets Ther 6: 281-7.

18. le Sage C, Nagel R, Egan DA, Schrier M, Mesman E, et al. (2007) Regulation of the $\mathrm{p} 27(\mathrm{Kip} 1)$ tumor suppressor by miR-221 and miR-222 promotes cancer cell proliferation. EMBO J 26 (15): 3699-708. possesses the advantages of low cost, convenience, and noninvasion, resulting in an effective method in monitoring cancer progression as well as assessing therapeutic efficacy in future. Considering the paucity of relevant data, further investigation and more studies are needed to focus on the relationship between the expression of miR-221 and cancer prognosis.

\section{Supporting Information}

Ghecklist S1 PRISMA checklist.

(DOC)

File S1 PRISMA flow diagram.

(DOG)

\section{Author Contributions}

Conceived and designed the experiments: JY CJY. Performed the experiments: JC NHS YX. Analyzed the data: JYZ JC. Contributed reagents/materials/analysis tools: JY. Wrote the paper: JYZ JY.

19. Di Martino MT, Gullà A, Cantafio ME, Lionetti M, Leone E, et al. (2013) In vitro and in vivo anti-tumor activity of miR-221/222 inhibitors in multiple myeloma. Oncotarget 4 (2): 242-55.

20. Lu C, Huang X, Zhang X, Roensch K, Cao O, et al. (2011) miR-221 and miR155 regulate human dendritic cell development, apoptosis, and IL-12 production through targeting of p27kip1, KPC1, and SOCS-1. Blood 117 (16): 4293-303.

21. Pineau P, Volinia S, McJunkin K, Marchio A, Battiston C, et al. (2010) miR-221 overexpression contributes to liver tumorigenesis. Proc Natl Acad Sci U S A 107 (1): 264-9.

22. Visone R, Russo L, Pallante P, De Martino I, Ferraro A, et al. (2007) MicroRNAs (miR)-221 and miR-222, both overexpressed in human thyroid papillary carcinomas, regulate p27Kipl protein levels and cell cycle. Endocr Relat Cancer 14 (3): 791-8.

23. Sun T, Wang Q, Balk S, Brown M, Lee GS, et al. (2009) The role of microRNA221 and microRNA-222 in androgen-independent prostate cancer cell lines. Cancer Res 69 (8): 3356-63.

24. Kawaguchi T, Komatsu S, Ichikawa D, Morimura R, Tsujiura M, et al. (2013) Clinical impact of circulating miR-221 in plasma of patients with pancreatic cancer. Br J Cancer 108 (2): 361-9.

25. Galardi S, Mercatelli N, Farace MG, Ciafrè SA (2011) NF-kB and c-Jun induce the expression of the oncogenic miR-221 and miR-222 in prostate carcinoma and glioblastoma cells. Nucleic Acids Res 39 (9): 3892-902.

26. Chun-Zhi Z, Lei H, An-Ling Z, Yan-Chao F, Xiao Y, et al. (2010) MicroRNA221 and microRNA-222 regulate gastric carcinoma cell proliferation and radioresistance by targeting PTEN. BMC Cancer 10: 367.

27. Yaman Agaoglu F, Kovancilar M, Dizdar Y, Darendeliler E, Holdenrieder S, et al. (2011) Investigation of miR-21, miR-141, and miR-221 in blood circulation of patients with prostate cancer. Tumour Boil 32 (3): 583-8.

28. Zheng C, Yinghao S, Li J (2012) MiR-221 expression affects invasion potential of human prostate carcinoma cell lines by targeting DVL2. Med Oncol 29 (2): 815-22.

29. Hong F, Li Y, Xu Y, Zhu L (2013) Prognostic significance of serum microRNA221 expression in human epithelial ovarian cancer. J Int Med Res 41 (1): 64-71.

30. Li J, Wang Y, Yu W, Chen J, Luo J (2011) Expression of serum miR-221 in human hepatocellular carcinoma and its prognostic significance. Biochem Biophys Res Commun 406 (1): 70-3.

31. Pu XX, Huang GL, Guo HQ Guo CC, Li H, et al. (2010) Circulating miR-221 directly amplified from plasma is a potential diagnostic and prognostic marker of colorectal cancer and is correlated with p53 expression. J Gastroenterol Hepatol 25 (10): 1674-80.

32. Guo HQ, Huang GL, Guo CC, Pu XX, Lin TY (2010) Diagnostic and prognostic value of circulating miR-221 for extranodal natural killer/T-cell lymphoma. Dis Markers 29 (5): 251-8.

33. Papaconstantinou IG, Manta A, Gazouli M, Lyberopoulou A, Lykoudis PM, et al. (2013) Expression of microRNAs in patients with pancreatic cancer and its prognostic significance. Pancreas 42 (1): 67-71.

34. Ogawa T, Enomoto M, Fujii H, Sekiya Y, Yoshizato K, et al. (2012) MicroRNA-221/222 upregulation indicates the activation of stellate cells and the progression of liver fibrosis. Gut 61 (11): 1600-9.

35. Gimenes-Teixeira HL, Lucena-Araujo AR, Dos Santos GA, Zanette DL, Scheucher PS, et al. (2013) Increased expression of miR-221 is associated with shorter overall survival in T-cell acute lymphoid leukemia. Exp Hematol Oncol $2(1): 10$. 
36. Zhang C, Zhang J, Hao J, Shi Z, Wang Y, et al. (2012) High level of miR-221/ 222 confers increased cell invasion and poor prognosis in glioma. J Transl Med 10: 119 .

37. Ilhan-Mutlu A, Wöhrer A, Berghoff AS, Widhalm G, Marosi C, et al. (2013) Comparison of microRNA expression levels between initial and recurrent glioblastoma specimens. J Neurooncol 112 (3): 347-54.

38. Liu K, Li G, Fan C, Diao Y, Wu B, et al. (2012) Increased Expression of MicroRNA-221 in gastric cancer and its clinical significance. J Int Med Res 40 (2): 467-74.

39. Yoon SO, Chun SM, Han EH, Choi J, Jang SJ, et al. (2011) Deregulated expression of microRNA-221 with the potential for prognostic biomarkers in surgically resected hepatocellular carcinoma. Hum Pathol 42 (10): 1391-400.

40. Radojicic J, Zaravinos A, Vrekoussis T, Kafousi M, Spandidos DA, et al. (2011) MicroRNA expression analysis in triple-negative (ER, PR and Her2/neu) breast cancer. Cell Cycle 10 (3): 507-17.

41. Huang JJ, Yu J, Li JY, Liu YT, Zhong RQ (2012) Circulating microRNA expression is associated with genetic subtype and survival of multiple myeloma. Med Oncol 29 (4): 2402-8.

42. Yuan Q Loya K, Rani B, Möbus S, Balakrishnan A, et al. (2013) MicroRNA221 overexpression accelerates hepatocyte proliferation during liver regeneration. Hepatology 57 (1): 299-310.

43. Rong M, Chen G, Dang Y (2013) Increased MiR-221 expression in hepatocellular carcinoma tissues and its role in enhancing cell growth and inhibiting apoptosis in vitro. BMC Cancer 13: 21.

44. Karakatsanis A, Papaconstantinou I, Gazouli M, Lyberopoulou A, Polymeneas G, et al. (2013) Expression of microRNAs, miR-21, miR-31, miR-122, miR-145, miR-146a, miR-200c, miR-221, miR-222, and miR-223 in patients with hepatocellular carcinoma or intrahepatic cholangiocarcinoma and its prognostic significance. Mol Carcinog 52 (4): 297-303.

45. Coskun E, Neumann M, Schlee C, Liebertz F, Heesch S, et al. (2013) MicroRNA profiling reveals aberrant microRNA expression in adult ETP-ALL and functional studies implicate a role for miR-222 in acute leukemia. Leuk Res 37 (6): $647-56$

46. Zhou YL, Liu C, Dai XX, Zhang XH, Wang OC (2012) Overexpression of miR-221 is associated with aggressive clinicopathologic characteristics and the BRAF mutation in papillary thyroid carcinomas. Med Oncol 29 (5): 3360-6.

47. Gramantieri L, Fornari F, Ferracin M, Veronese A, Sabbioni S, et al. (2009) MicroRNA-221 targets Bmf in hepatocellular carcinoma and correlates with tumor multifocality. Clin Cancer Res 15 (16): 5073-81.

48. Kang SG, Ha YR, Kim SJ, Kang SH, Park HS, et al. (2012) Do microRNA 96, 145 and 221 expressions really aid in the prognosis of prostate carcinoma? Asian J Androl 14 (5): 752-7.

49. Amankwah EK, Anegbe E, Park H, Pow-Sang J, Hakam A, et al. (2013) miR-21, miR-221 and miR-222 expression and prostate cancer recurrence among obese and non-obese cases. Asian J Androl 15 (2): 226-30.

50. Duncavage E, Goodgame B, Sezhivan A, Govindan R, Pfeifer J (2010) Use of microRNA expression levels to predict outcomes in resected stage I non-small cell lung cancer. J Thorac Oncol 5 (11): 1755-63.
51. Hanna JA, Wimberly H, Kumar S, Slack F, Agarwal S, et al. (2012) Quantitative analysis of microRNAs in tissue microarrays by in situ hybridization. Biotechniques 52 (4): 235-45.

52. Wang Y, Li Z, He C, Wang D, Yuan X, et al. (2010) MicroRNAs expression signatures are associated with lineage and survival in acute leukemias. Blood Cells Mol Dis 44 (3): 191-7.

53. Wurz K, Garcia RL, Goff BA, Mitchell PS, Lee JH, et al. (2010) MiR-221 and MiR-222 alterations in sporadic ovarian carcinoma: Relationship to CDKN1B, CDKNIC and overall survival. Genes Chromosomes Cancer 49 (7): 577-84.

54. Spahn M, Kneitz S, Scholz CJ, Stenger N, Rüdiger T, et al. (2010) Expression of microRNA-221 is progressively reduced in aggressive prostate cancer and metastasis and predicts clinical recurrence. Int J Cancer 127 (2): 394-403.

55. Parmar MK, Torri V, Stewart L (1998) Extracting summary statistics to perform meta-analyses of the published literature for survival endpoints. Stat Med 17 (24): 2815-34.

56. Williamson PR, Smith CT, Hutton JL, Marson AG (2002) Aggregate data metaanalysis with time-to-event outcomes. Stat Med 21 (22): 3337-51.

57. Tierney JF, Stewart LA, Ghersi D, Burdett S, Sydes MR (2007) Practical methods for incorporating summary time-to-event data into metaanalysis. Trials 8: 16 .

58. DerSimonian R, Laird N (1986) Meta-analysis in clinical trials. Control Clin Trials 7 (3): 177-88.

59. Egger M, Davey Smith G, Schneider M, Minder C (1997) Bias in meta-analysis detected by a simple, graphical test. BMJ 315 (7109): 629-34.

60. Ferracin M, Veronese A, Negrini M (2010) Micromarkers: miRNAs in cancer diagnosis and prognosis. Expert Rev Mol Diagn 10: 297-308.

61. Kim DJ, Linnstaedt S, Palma J, Park JC, Ntrivalas E, et al. (2012) Plasma components affect accuracy of circulating cancer-related microRNA quantitation. J Mol Diagn 14 (1): 71-80.

62. Igoucheva O, Alexeev V (2009) MicroRNA-dependent regulation of cKit in cutaneous melanoma. Biochem Biophys Res Commun 379 (3): 790-4.

63. Yazici H, Zipprich J, Peng T, Akisik EZ, Tigli H, et al. (2009) Investigation of the miR16-1 $(\mathrm{C}>\mathrm{T})+7$ Substitution in Seven Different Types of Cancer from Three Ethnic Groups. J Oncol 2009: 827532.

64. Bovell LC, Shanmugam G, Putcha BD, Katkoori VR, Zhang B, et al. (2013) The Prognostic Value of MicroRNAs Varies with Patient Race/Ethnicity and Stage of Colorectal Cancer. Clin Cancer Res 19 (14): 3955-65.

65. Huang RS, Gamazon ER, Ziliak D, Wen Y, Im HK, et al. (2011) Population differences in microRNA expression and biological implications. RNA Biol 8 (4): $692-701$.

66. Wiesner C, Nabha SM, Dos Santos EB, Yamamoto H, Meng H, et al. (2008) Ckit and its ligand stem cell factor: potential contribution to prostate cancer bone metastasis. Neoplasia 10 (9): 996-1003.

67. Hayes DF, Isaacs C, Stearns V (2001) Prognostic factors in breast cancer: current and new predictors of metastasis. J Mammary Gland Biol Neoplasia 6 (4): $375-92$. 